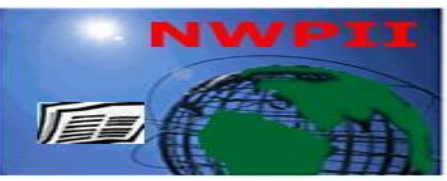

American Journal of Biomedical Sciences

ISSN: 1937-9080

nwpii.com/ajbms

\title{
Factors Affecting Medical Laboratory Science Student's Preference for Specialization in Nigeria
}

\section{Theophilus Ogie ERAMEH ${ }^{1}$, Micheal Awol OKUNGBOWA ${ }^{2}$ and Bolaji Efosa ODIGIE* ${ }^{2}$}

${ }^{1}$ Department of Medical Laboratory Science, Faculty of Health Sciences, College of Medicine, Igbinedion University, Okada, Edo State, Nigeria.

${ }^{2}$ Department of Medical Laboratory Science, School of Basic Medical Sciences, College of Medical Sciences, University of Benin, Nigeria.

*Corresponding Author

Bolaji Efosa ODIGIE

Histopathology Unit

Department of Medical Laboratory Science,

School of Basic Medical Sciences,

College of Medical Sciences,

University of Benin, Benin City,

Edo State, Nigeria.

Email: bolaji.odigie@uniben.edu

GSM: +2348023345132

Received:15 December 2017 ; | Revised:02 January 2018; | Accepted:28 February 2018

\begin{abstract}
Medical Laboratory Science (MLS) students in higher institutions in Nigeria have been difficult in choosing their preferred area of specializations. Our study investigated the factors affecting MLS student's specialization in the sub-discipline of the profession in Nigeria. A descriptive cross-sectional design with a structured questionnaire was used for this survey. The questionnaire was validated and reliability test was conducted before a final draft copy. The study followed due ethics clearance and informed consent protocols, the collected data was analyzed using SPSS package version 16.0 and the level of significance was set at $\mathrm{p} \leq$ 0.05. Five hundred and five (505) respondents (students), 287 females and 218 males from 3 Universities presently accredited to admit MLS students in Edo State, Nigeria, participated in the survey. About 152 (53.1\%) female and 92(42.2\%) male students indicated that job description was the major factor affecting specialization in the various sub-fields of MLS. While, 215/505(42.57\%) of the respondents indicated that occupational hazard is the main factor that discourages student's decision towards specialization. The relationship between student's sex and the discouraging factor was statistically significant at $p<0.001$. Job description and occupational hazards associated with the various sub-specialties in MLS profession have been identified in this survey as the factors that may affect MLS students' preference for specialization. We, therefore, recommend that further studies be conducted with a wider scope as all the potential factors may not have been critically evaluated in this study.
\end{abstract}


Keywords: Specialties in Medical Laboratory Science, clinical chemistry, haematology, histopathology \& medical microbiology

\section{Introduction}

Medical Laboratory Science deals exclusively with a broad range of functions which are not limited to the analysis of body specimens from cells to tissues, organ, and systems of both humans and animals ${ }^{[1]}$. There are different nomenclatures for various countries in which the profession is domicile. In United States of America and Canada, the profession is referred to as Clinical Laboratory Science, United Kingdom (Biomedical Science), while Australia and New-Zealand retain the same nomenclature as Nigeria. Medical Laboratory Science students in Nigeria, presently specialize in any of the sub-disciplines like clinical chemistry, heamatology/ transfusion science, medical microbiology, and histopathology/cytopathology. In Nigeria, MLS students undertake the complete coursework approved by the Medical Laboratory Science Council of Nigeria in conjunction with the National Universities Commission from the first year to the fourth year. Specialization in a particular area of choice is done at the fifth year ${ }^{[1]}$, in which a student picks a particular area of specialization from the list of specialties earlier mentioned.

Advancement in knowledge has necessitated the need for medical students to diversify into the areas of choice ${ }^{[2]}$, and as such medical laboratory science is not left afar. The preference of specialties by the students is an integral part that constitutes the workforce in the smooth running of the health-care system ${ }^{[1]}$. If a nation must make progress, the citizens must be healthy, however, to make all citizens healthy, medical laboratory scientists must specialize in one of the critical areas of specialization to bridge the gap in the health sector, which leads to an efficient health-care delivery. We have noticed over time that MLS students find it difficult to choose a specific specialty when they get to the level in which specialization becomes necessary. We have also had a situation in which some students are yet to make up their minds even after the semester is halfway gone.
Issues of specialty preference have significant concerns for the majority of students in MLS, especially in Nigeria. There may be piecemeal of investigations that look into factors affecting medical student's specialization; however, no such studies in the field of Medical Laboratory Science in Nigeria have been undertaken in institutions offering MLS.

From the preceding, therefore, there is little or no information available for the Nigerian MLS students on how they make their career preferences at the point of specialization in a particular specialty. Our survey, therefore, investigated the factors affecting Medical Laboratory Science students towards their specialization preferences in Edo State, Nigeria.

\section{Materials and Methods}

\subsection{Study Design}

This study was a quasi-experimental multistage design. The technique utilized a combination of probability and none probability sampling method and sequential performance.

\subsection{Study Areas}

This study was conducted in Edo State, Nigeria. The areas in which Institutions for higher learning exists and with the Universities where MLS is taught are Ambrose Alli University (AAU), Ekpoma; University of Benin, Benin City, and Igbinedion University, Okada, all in Edo State, Nigeria. Note: Edo University at the moment offers MLS as a course but has only 100level students, which fall within the exclusion criteria

\subsection{Sample Size and Study participants}

All students admitted to the Department of Medical Laboratory Science in Edo State-based universities from second year to fourth year of study were recruited and also participated in the survey. 


\subsection{Exclusion and Inclusion Criteria}

Students in their first and final years were excluded from this survey. Reasons being that at the first year, the students are still in the Faculty of Sciences and as such are yet to know what Medical Laboratory Science is all about. Meanwhile, the final year students have already entered into their various areas of specialization thereby making them be excluded.

\subsection{Data Collection}

Questionnaires were administered to the students at the end of the student's general assembly meeting in which all levels of the student is expected to be present along with an information sheet, which explained the nature of the survey and the anonymity of responses ${ }^{[3]}$. The questionnaire was structured and administered by the researchers with a keen supervision. The structured questionnaire contained two segments (A \& B). The first segment of the questionnaire centered on sex, age, religion, mode of admission, year of study and present class. The other segment centered on student's attitude towards specialization as well as factors that may discourage/influence their choices (Appendix I). Question and answer in a closed-style were used, the questions were 'tick-box' responses to aid speedy completion, and to make quantitative statistical analysis simple ${ }^{[4]}$. After a voluntary completion of the questionnaires, they were deposited in a box at the end of the meeting one after the other with a strict monitoring to ensure that the rules earlier explained to the students were optimally followed.

\subsection{Validity of Research Tool}

The questionnaire was given to about five different experts in the Department of Medical Laboratory Science (one expert per University of interest and the fifth one was given to a neutral expert from another University that is not related to the study area) for content and face validity. These experts made sure that all the research questions are comprehensively covered and that none of the questions were overloaded at the expense of others (content validity). They also assessed the arrangement and format of the questions such as its attraction (face validity). Furthermore, they also investigated the actual measure of the outcome variables of the study, or if anything it purports to measure as being left out (construct validity).

\subsection{Reliability of Research Tool}

A pilot study was conducted using about $10 \%$ of the total participants in one shot (just once) with a similar characteristic to assess the technique of the questionnaire administration, the adequacy of the questionnaire items, knowledge of the research questions by the pilot participants and to reveal its visibility and consistency. Others include problems that may arise during the study and all unforeseen problems that should be corrected before the actual study begins. The data for the pilot study was however collated using the split-half method, and the completed questionnaire, which was prenumbered were divided into two groups ( $\mathrm{X}$ and $\mathrm{Y}$ ) of 5\% using the old, and even values approach and the results compared in testing the reliability of the research tool (questionnaire).

\subsection{Ethics clearance and Informed Consent}

Full ethical approval from the ethics and Investigations Committee of the Edo State Ministry of Health for Ethics matters was obtained before the study with clearance number HM1208/256. Volunteers from the Department of Medical Laboratory Science students within Edo State-based Universities and of different ages were recruited by the simple random method. The actual intention of the study was adequately described to the students after assuring secrecy of the first order. Verbal informed consent was mandatory by the students were written informed consent becomes unachievable, which was conducted in the presence of a witness who is either the course adviser, senior lecturer in the Department or staff adviser before the questionnaire was administered ${ }^{[5]}$.

\subsection{Data Analysis}

The data was analyzed using Statistical Package for Social Sciences (SPSS) package version 16.0. Descriptive data are given as frequencies and percentages, and tables and charts were used to present results, where necessary. ANOVA was used to analyze the relationship between demographic data and factors most likely 
to affect students' decision, factors discouraging towards histopathology specialization. The strength of association was analyzed using Chi-square test.

The level of significance was set at $p \leq 0.05$.

\section{Results}

The respondents were distributed among all the age groups. Age group "15-20" accounted for the highest number of respondents with $99(41.3 \%)$ of them from Ambrose Alli University (AAU), $74(42.3 \%)$ from University of Benin (UNIBEN) and $29(32.2 \%)$ from Igbinedion University, Okada (Table 1). More than $80 \%$ of the respondents were single across the three schools. Majority of the respondents, AAU (58.3\%), UNIBEN (53.2\%) and Igbinedion University (60\%) were female (Table 1). More than half $(53.1 \%)$ of the students indicated that job description is the major factor affecting their preference towards specialization (Table 2). However, $81(37.2 \%)$ and $92(42.2 \%)$ of the male student's decisions and Students' perception respondents indicated that pathology interferences and job descriptions are the discouraging factors towards a preference for specialization (Table 2). The attitude of MLS staff as an influence towards students specialization showed that MLS staff across the three institutions in Edo State are student' s friendly (Table 3 ). The association between sex and preferential factor in specialization was statistically significant at $\mathrm{p}<0.05$ (Table 4). Notably, none of the respondents within the age group "35-40" and ">40" choose an attitude of other MLS scientists as a hindrance to specialization (Table 4). On the other hand, 215/505 of the respondents, which amount to $42.57 \%$, indicated that occupational hazard is seen as the main factor that discourages student' $\mathrm{s}$ decision towards specialization in any of the MLS sub-specialties (Table 5).

Table 1: Respondents Demographic Data

\begin{tabular}{|c|c|c|c|c|c|c|c|}
\hline & & \multicolumn{2}{|c|}{$\begin{array}{l}\text { AAU } \\
(n=240)\end{array}$} & \multicolumn{2}{|c|}{$\begin{array}{l}\text { UNIBEN } \\
(n=175)\end{array}$} & \multicolumn{2}{|c|}{$\begin{array}{l}\text { IGBINEDION } \\
(\mathbf{n}=90)\end{array}$} \\
\hline & & Freq. & $\%$ & Freq. & $\%$ & Freq. & $\%$ \\
\hline \multirow[t]{2}{*}{ Sex } & Male & 100 & 41.7 & 82 & 46.9 & 36 & 40.0 \\
\hline & Female & 140 & 58.3 & 93 & 53.2 & 54 & 60.0 \\
\hline \multirow[t]{7}{*}{ Age } & $<15$ & 50 & 20.8 & 8 & 4.6 & 1 & 1.1 \\
\hline & $15-20$ & 99 & 41.3 & 74 & 42.3 & 29 & 32.2 \\
\hline & $21-25$ & 79 & 32.9 & 74 & 42.3 & 35 & 38.9 \\
\hline & $26-30$ & 8 & 3.3 & 13 & 7.4 & 13 & 14.4 \\
\hline & $31-35$ & 1 & 0.4 & 5 & 2.9 & 5 & 5.6 \\
\hline & $35-40$ & 1 & 0.4 & 1 & 0.6 & 5 & 5.6 \\
\hline & $>40$ & 2 & 0.8 & 8 & 4.6 & 2 & 2.2 \\
\hline \multirow[t]{2}{*}{ Marital Status } & Single & 223 & 92.9 & 163 & 93.1 & 73 & 81.1 \\
\hline & Married & 17 & 7.1 & 12 & 6.9 & 17 & 18.9 \\
\hline \multirow[t]{4}{*}{ Religion } & Christianity & 207 & 86.3 & 156 & 89.1 & 59 & 65.6 \\
\hline & Traditional & 14 & 5.8 & 13 & 7.4 & 10 & 11.1 \\
\hline & Muslim & 9 & 3.8 & 4 & 2.3 & 19 & 21.1 \\
\hline & Others & 10 & 4.2 & 2 & 1.2 & 2 & 2.2 \\
\hline
\end{tabular}


Table 2: Factors affecting the preference of MLS students towards Specialization $(n=505)$

\begin{tabular}{lll}
\hline & Frequency & Percentage \\
\hline Pathology dominance & 141 & 27.9 \\
Attitude of other MLS scientist & 41 & 8.1 \\
& & \\
Job description & 243 & 48.1 \\
Unsure & 80 & 15.8 \\
\hline
\end{tabular}

Table 3: Attitude of MLS staff towards students

\begin{tabular}{lllllll}
\hline \multirow{2}{*}{ Attitude } & AAU & \multicolumn{3}{c}{ UNIBEN } & \multicolumn{2}{c}{ IGBINEDION } \\
\cline { 2 - 7 } & Freq & \% & Freq & \% & Freq & \% \\
\hline Friendly & 179 & 74.6 & 121 & 69.1 & 38 & 42.2 \\
Not Friendly & 15 & 6.3 & 7 & 4.0 & 27 & 30.0 \\
Unsure & 46 & 19.2 & 46 & 26.3 & 25 & 27.8 \\
& & & & & & \\
\hline
\end{tabular}

Table 4: Relationship between demographic data and factors discouraging decision to specialize in MLS

\begin{tabular}{|c|c|c|c|c|c|}
\hline & \multicolumn{4}{|c|}{$\begin{array}{l}\text { Factors Affecting Specialization } \\
\text { Frequency }(\%)\end{array}$} & \multirow[t]{2}{*}{$\begin{array}{l}\text { Test Statistics } \\
\text { p-value }\end{array}$} \\
\hline & $\begin{array}{l}\text { Pathology } \\
\text { Interferences }\end{array}$ & $\begin{array}{l}\text { Attitude of other } \\
\text { MLS Scientists }\end{array}$ & $\begin{array}{l}\text { Job } \\
\text { Descriptions }\end{array}$ & Unsure & \\
\hline \multicolumn{6}{|l|}{ Sex } \\
\hline Male & $81(37.2)$ & 21(9.6) & $92(42.2)$ & $24(11.0)$ & $\chi 2=19.993$ \\
\hline Female & $60(21.0)$ & $21(7.3)$ & $152(53.1)$ & $53(18.5)$ & p-value $=<0.001 *$ \\
\hline \multicolumn{6}{|l|}{ Age } \\
\hline$<15$ & $17(28.8)$ & $6(10.2)$ & $21(35.6)$ & $15(25.4)$ & $\chi^{2}=26.437$ \\
\hline $15-20$ & $51(25.2)$ & $12(5.9)$ & $103(51.0)$ & $36(17.8)$ & $\stackrel{\sim}{\mathrm{P}}$-value $=0.90$ \\
\hline $21-25$ & $49(26.1)$ & $17(9.0)$ & $99(52.7)$ & $23(12.2)$ & \\
\hline $26-30$ & $13(38.2)$ & $6(17.6)$ & $12(35.3)$ & $3(8.8)$ & \\
\hline $31-35$ & $6(54.5)$ & $1(9.1)$ & $4(36.4)$ & $0(0.0)$ & \\
\hline $35-40$ & $3(50.0)$ & $0(0.0)$ & $3(50.0)$ & $0(0.0)$ & \\
\hline$>40$ & $2(40.0)$ & $0(0.0)$ & $2(40.0)$ & $1(20.0)$ & \\
\hline \multicolumn{6}{|c|}{ Marital Status } \\
\hline Single & $123(26.8)$ & $37(8.1)$ & $224(48.8)$ & $75(16.3)$ & $\chi^{2}=5.529$ \\
\hline Married & $18(39.1)$ & $5(10.9)$ & $20(43.5)$ & $3(6.5)$ & $\mathrm{p}$-value $=0.137$ \\
\hline \multicolumn{6}{|l|}{ Religion } \\
\hline Christianity & $109(25.8)$ & $32(7.6)$ & $212(50.2)$ & $69(16.4)$ & \\
\hline Traditional & $18(48.6)$ & $4(10.8)$ & $13(35.1)$ & $2(5.4)$ & \\
\hline Muslim & $7(21.9)$ & $5(15.6)$ & $14(43.8)$ & $6(18.8)$ & $\chi^{2}=18.476$ \\
\hline Others & $7(53.8)$ & $1(7.7)$ & $4(30.8)$ & $1(7.7)$ & p-value $=0.03 *$ \\
\hline
\end{tabular}

$*=$ Significant 
Table 5: Factors discouraging decision to specialize in MLS sub-specialties $(n=505)$

\begin{tabular}{lll}
\hline & Frequency & Percentage \\
\hline Occupational hazard & 215 & 42.57 \\
Working environment & 169 & 33.47 \\
& & \\
Nature of specimens & 83 & 16.44 \\
Unsure & 38 & 7.52 \\
\hline
\end{tabular}

\section{Discussion}

Career options and specialty preferences ${ }^{[2]}$ by MLS students are essential to the workforce of the health sector. Proper planning by healthcare sector planners ${ }^{[2]}$ will bring about an outstanding balance in the health-care delivery to the overwhelming Nigerian populace. In this study, gender differences ${ }^{\text {[2] }}$ showed that females participated more than their male counterparts. Age group 15-20 showed more responses than others, single students more than the married and the Christian religion more than other religions in the institutions surveyed (Table 1). This revelation is attributable to existing factors in Nigeria educational system, which is similar to what has been reported in Nigeria and some parts of the world ${ }^{[2-5]}$. The younger students are admitted in place of the old, while; singles are preferred for admission than the married. Edo State being a predominantly dominated Christian state may have been responsible for the religious bias in admission status. Sex $\mathrm{p}<0.001$ (Table 2), age $\mathrm{p}<0.036$ (Table 4) and religion $p<0.03$ (Tabe $2 \& 4$ ) are statistically significant and are comparable to what have been reported in notable journals both locally and internationally ${ }^{[6,7]}$.

Student's attitude has been grossly influenced by numerous factors in similar studies that were not captured in the present survey ${ }^{[7-10]}$. The attitude of an individual towards a particular specialty may reflect in the overall performances of the candidate ${ }^{[8]}$. Hence, we noticed that the attitude of lecturers and scientists towards specialization revealed that they are friendly with the students, and was evenly reflected in all institutions in which the survey occurred (Table 2). Considering the relationship between staff and students in the schools visited, most students agreed that MLS lecturers and scientists are very friendly (Table 2). This report represents the general views and opinion of students from the three Universities that participated in the survey. Recall that the attitude of a teacher to their students may positively or negatively influence/ affect a student's decision or preference for one specialty as against the other ${ }^{[9,10]}$. In buttress of our point, specialty choices or preferences among graduating medical students at the University of Calabar, Nigeria has been influenced by the attitude of the students to the various fields of specialization ${ }^{[10]}$. Our study, however, corroborates a similar study by Odigie and Erameh ${ }^{[11]}$ in which majority of MLS staff are reported to be friendly to students in the Department of MLS in Nigeria, with a piecemeal reservation to some scrupulous lecturers who bully and lord over their students.

Numerous investigators have tried to study the factors that influence students' preferences towards the choice of medical specialization. ${ }^{[2,3 \& 12]}$ Some postulations have it that the primary effects were students' characteristics, such as controllable lifestyles ${ }^{[2]}$ whereas another group sees the factors as relating to medical school characteristics such as orientation towards research ${ }^{[3]}$. However, medical educators are engrossed in the educational influences ${ }^{[4]}$; like the departmental role models ${ }^{[11]}$, course curriculum, and primary care experiences. These influential factors are more readily adjustable compared to such factors like institution's relative research intensity or students' long-held values ${ }^{[4]}$.

The most debated factors affecting the preference for specialization selection from the student stand points are job description, and occupational hazard that is related to the sub- 
specialties in MLS. Others are pathologist dominance, attitude of other MLS scientists in the hospital/ university, working environment, and the nature of specimens received in the different subspecialties. Note that the type of specimen that is received in a laboratory may bring about bias in the choice of specialization ${ }^{[11]}$. Factors such as working environment and peculiarities in occupational hazard differ from one hospital to another. MLS staff who work in an acrimonious environment, which is rivalry dominated by the different health professionals cannot be compared to what is obtainable in the advanced countries of the world [11]. Occupational hazards play vital roles in decision making especially when it has to do with hospital related hazards ${ }^{[11]}$. Our findings matched with Kakkar and Dahiya ${ }^{[13]}$ as well as Jadhav et al. ${ }^{[14]}$ in which one or more and similar factors were discussed extensively. However, our study did not agree with Kumar et al. ${ }^{[15]}$ in which, the future career interests and factors that influence

undergraduate medical students' choice of specialty was evaluated. The study revealed that parental influences are more on female students than their male counterparts and thus suggests that student's parental influence is a major factor to reckon with. The differences may be attributed to the study aim and focus. Recall that our focus was on MLS students compared to the former ${ }^{[15]}$, which focused on medical students in China, Malaysia and some regions of south Asia. The present study was limited to Edo State based universities. Therefore, it may not represent the opinion of the generality of the student's responses across other universities in Nigeria who offer MLS as a course.

\section{Conclusions}

Job description and hazards associated with the various sub-specialties in MLS profession have been identified in this survey as the factors affecting MLS students' preference for specialization. Other factors like acrimonious working environment and the nature of specimens received in some specialties have also been noted. Identifying the factors affecting MLS students' preference for specialization could be a great task; however, without clear understanding of the discouraging factors, the influencing factors might not be critically evaluated and permanently addressed. We, therefore, recommend that further studies be conducted in this direction and with a wider scope.

\section{Financial Support and Sponsorship}

This survey is self-sponsored.

\section{Conflicts of Interest}

No conflicts declared.

\section{Acknowledgements}

Authors appreciate the members of Sexual Health Concerns for Commercial Sex Workers (SHCCSW) Research Group, University of Benin for providing a workforce for the administration of questionnaires.

\section{Contributors}

EOT, OBE and OMA immensely contributed to the drafting of the manuscript. EOT and OMA contributed to the conception and design of the study. All authors contributed to acquisition of the data and field exercise. OBE and OMA contributed to data analysis and interpretation. All authors critically revised the manuscript for important intellectual content. EOT, OBE and OMA read and approved the final draft. All authors made significant contributions that warrant authorship. OBE acted as corresponding author on behalf of the other authors.

\section{References}

1 Agbonlahor, D.E.; Ihimekpen, G.; Okara, G.C. Evaluation of Medical Laboratory Science Profession in Nigeria. AMLSN. 2014; 6-91. http://www.amlsn.org.ng/

2 Saigal P, Takemura Y, Nishiue T, Fetters MD. Factors considered by medical students when formulating their specialty preferences in Japan: findings from a qualitative study. $\boldsymbol{B M C}$ Med Educ 2007; 7: 31 [PMID: 17848194 DOI: $\underline{10.1186 / 1472-6920-7-31]}$ 
3 Khader Y, Al-Zoubi D, Amarin Z, Alkafagei A, Khasawneh M, Burgan S, El Salem K, Omari M. Factors affecting medical students in formulating their specialty preferences in Jordan. BMC Med Educ 2008; 8: 32 [PMID: 18501004 DOI: $10.1186 / 1472-6920-8-32]$

4 Ilegbedion, I.G.; Onyije, F.M.; Ezeama, J.O. Awareness and Attitude of Medical Laboratory Science Students towards Specializing in Histopathology. Afri J Basic \& Appl Sci., 2013; 5(4): 188-192. DOI: 10.5829/idosi.ajbas.2013.5.4.1137

5 Mainasara, A.S.; Ibrahim, K.K.; Dallatu, M.K.; Garba, A.; Sanusi, M.; Mohammed, M.O. Students ' Interests in a Particular Area (Specialty). In the Profession of Medical Laboratory Science, Faculty of Medical Laboratory Sciences, UDU, Sokoto, NorthWestern Nigeria. Asian J Med \& Health, 2016; 1: 1-8.

6 Khan FA, Minai FN, Siddiqui S. Anaesthesia as a career choice in a developing country; effect of clinical clerkship. J Pak Med Assoc 2011; 61(11): 1052-1056 [PMID: 22125976]

7 Abioye IA, Ibrahim NA, Odesanya MO, Wright KO. The future of trauma care in a developing country: interest of medical students and interns in surgery and surgical specialties. Int J Surg 2012; 10(4): 209-212 [PMID: 22449830 DOI: 10.1016/j.ijsu.2012.03.003]

8 Mohammed, Y.; Zailani, S.B.; Galadima, G.B.; Saidu, K. Perception of final year medical students about the choice of medical microbiology as a specialty. Orient J Med., 2015; 27(1-2): 28-33. https://www.ajol.info/index.php/ojm/article/vie $\underline{\mathrm{w} / 117953}$
9 Smith, A.; Mannion, S. Irish patient' $\mathrm{s}$ knowledge and perception of anaesthesia. Ir Med J., 2013; 106(2):50 - 52. https://www.ncbi.nlm.nih.gov/pubmed/234723 86 PMID: 23472386

10 Oku, O.O.; Oku, A.O.; Edentekhe, T.; Kalu, Q. Specialty choices among graduating medical students in University of Calabar, Nigeria: implications for anesthesia practice. Ain-

Shams J Anesthesiol., 2014; 7(4):485-490.

11 Odigie, B.E.; Erameh, T.O. Knowledge and Awareness of Histopathology Specialty by Medical Laboratory Science Undergraduate Students in Edo State. Sokoto J. Med Lab Sci., 2017; 2(4): 44-52. https://sokjmls.com.ng/

12 Pawelczyk A, Pawelczyk T, Bielecki J. [The effect of some factors on medical student specialty choice of non-primary care--a synthesis of the literature]. Pol Merkur Lekarski 2007; 22(132): 575-579 [PMID: 17874633]

13 Kakkar AK , Dahiya N. Factors Affecting Choice of Future Specialty among Medical Students. N Am J Med Sci 2014; 6(4): 181182 [PMID: 24843852 DOI:10.4103/19472714.131247]

14 Jadhav, S.J.; Yeravadekar, R.; Shrivastava, S.; Kulkarni, M. Career choices in allied health: A study of influencing factors on students of medical technology at an Indian University. Int J Health Sci., 2013; 2(4):256-259. DOI: $10.4103 / 2278-344 X .126714$

15 Kakkar AK, Dahiya N. Factors Affecting Choice of Future Specialty among Medical Students. N Am J Med Sci 2014; 6(4): 181182 [PMID: 24843852 DOI: 10.4103/19472714.131247] 